\title{
Nuclear $\beta$-catenin and CD44 upregulation characterize invasive cell populations in non-aggressive MCF-7 breast cancer cells
}

\author{
Masahiro Uchino ${ }^{1 *}$, Hiroko Kojima ${ }^{1,3}$, Kenta Wada ${ }^{1,4}$, Mika Imada ${ }^{2,5}$, Fumitoshi Onoda ${ }^{2}$, Hiroyuki Satofuka ${ }^{1}$,
} Takahiko Utsugi ${ }^{1}$, Yasufumi Murakami ${ }^{1,2}$

\begin{abstract}
Background: In breast cancer cells, the metastatic cell state is strongly correlated to epithelial-to-mesenchymal transition (EMT) and the CD44 $/$ CD24 stem cell phenotype. However, the MCF-7 cell line, which has a luminal epithelial-like phenotype and lacks a CD44 $/$ CD24 subpopulation, has rare cell populations with higher Matrigel invasive ability. Thus, what are the potentially important differences between invasive and non-invasive breast cancer cells, and are the differences related to EMT or CD44/CD24 expression?

Methods: Throughout the sequential selection process using Matrigel, we obtained MCF-7-14 cells of opposite migratory and invasive capabilities from MCF-7 cells. Comparative analysis of epithelial and mesenchymal marker expression was performed between parental MCF-7, selected MCF-7-14, and aggressive mesenchymal MDA-MB-231 cells. Furthermore, using microarray expression profiles of these cells, we selected differentially expressed genes for their invasive potential, and performed pathway and network analysis to identify a set of interesting genes, which were evaluated by RT-PCR, flow cytometry or function-blocking antibody treatment.
\end{abstract}

Results: MCF-7-14 cells had enhanced migratory and invasive ability compared with MCF-7 cells. Although MCF-714 cells, similar to MCF-7 cells, expressed E-cadherin but neither vimentin nor fibronectin, $\beta$-catenin was expressed not only on the cell membrane but also in the nucleus. Furthermore, using gene expression profiles of MCF-7, MCF-7-14 and MDA-MB-231 cells, we demonstrated that MCF-7-14 cells have alterations in signaling pathways regulating cell migration and identified a set of genes (PIK3R1, SOCS2, BMP7, CD44 and CD24). Interestingly, MCF-714 and its invasive clone CL6 cells displayed increased CD44 expression and downregulated CD24 expression compared with MCF-7 cells. Anti-CD44 antibody treatment significantly decreased cell migration and invasion in both MCF-7-14 and MCF-7-14 CL6 cells as well as MDA-MB-231 cells.

Conclusions: MCF-7-14 cells are a novel model for breast cancer metastasis without requiring constitutive EMT and are categorized as a "metastable phenotype", which can be distinguished from both epithelial and mesenchymal cells. The alterations and characteristics of MCF-7-14 cells, especially nuclear $\beta$-catenin and CD44 upregulation, may characterize invasive cell populations in breast cancer.

\section{Background}

Patients with breast cancer are at risk of metastasis throughout their lifetime because of the heterogeneous nature of breast cancer metastasis. Recent studies focusing on the early steps in the metastatic cascade, such as

\footnotetext{
* Correspondence: uchino@biomatrix.co.jp

${ }^{1}$ Neo-Technology Development Division, Bio Matrix Research Inc., 105

Higashifukai, Nagareyama, Chiba 270-0101, Japan

Full list of author information is available at the end of the article
}

epithelial-to-mesenchymal transition (EMT) and altered cell adhesion and motility, have demonstrated that aggressive cancer progression is correlated with the loss of epithelial characteristics and the gain of a migratory and mesenchymal phenotype [1]. In fact, the highly aggressive breast cancer cell line MDA-MB-231 exhibits mesenchymal-type behavior, whereas non-aggressive breast cancer cell line MCF-7 has a luminal epitheliallike phenotype $[2,3]$. 
In addition to the heterogeneous nature of metastasis, a solid tumor including breast cancer is comprised of heterogeneous cells in terms of their invasive and metastatic potential, as suggested by in vivo metastasis models [4] and an in vitro selection process using Matrigel $[5,6]$. Tumor heterogeneity has led to the "cancer stem cell hypothesis". Cancer stem cells share common characteristics with normal stem cells: ability to self-renew, differentiate, acquire drug resistance, survive anchorageindependently, and migrate. Furthermore, overlapping sets of molecules and pathways regulate both stem cell migration and cancer metastasis; therefore, cancer stem cells are assumed to contribute to metastasis as well as tumorigenesis [7]. In human breast tumors, the $\mathrm{CD} 44^{+} / \mathrm{CD} 24^{-/ \text {low }}$ phenotype has been reported to have stem cell properties [8]. Cell lines with high $\mathrm{CD}_{4} 4^{+} /$ CD24- cell numbers were basal/mesenchymal or myoepithelial types and more invasive than other cell lines. In contrast, non-aggressive epithelial MCF-7 cells lack a CD $44^{+} / \mathrm{CD}_{24}^{-}$subpopulation. Among CD $44^{+} / \mathrm{CD} 24^{-}-$ positive cell lines, MDA-MB-231 has the unique property of expressing a broad range of genes that favor bone and lung metastasis [9]. Although there remains a need to determine whether $\mathrm{CD} 44^{+} / \mathrm{CD} 24^{-/ \text {low }}$ cells are true breast cancer stem cells across all the various breast cancer subtypes, there seems to be a connection between EMT and CD44/CD24 expression in the mechanisms of breast cancer invasion and metastasis. Indeed, induction of EMT results in the acquisition of the CD $44^{\text {high }} / C D 24^{\text {low }}$ phenotype in immortalized human mammary epithelial cells [10].

In the current study, we demonstrated that nonaggressive epithelial MCF-7 cells had rare cell populations with higher Matrigel invasive ability. Throughout the sequential selection process using Matrigel, we obtained MCF-7-14 cells of opposite migratory and invasive capabilities from MCF-7 cells. Thus, what are the potentially important differences between invasive and non-invasive breast cancer cells, and are the differences related to EMT or CD44/CD24 expression? To answer these questions, comparative analysis of epithelial and mesenchymal marker expression was performed between MCF-7, MCF-7-14, and MDA-MB-231 cells. Furthermore, using microarray expression profiles of these cells, we selected differentially regulated genes for their invasive potential and performed pathway and network analysis to better characterize invasive cell populations in breast cancer.

\section{Methods}

\section{Cell culture}

Human breast cancer cell line MCF-7 was obtained from the Institute of Development, Aging and Cancer, Tohoku University. MDA-MB-231 was purchased from the American Type Culture Collection. Both cell lines were maintained in RPMI 1640 (Sigma-Aldrich, St. Louis, MO) containing 10\% fetal bovine serum (FBS) and an antibiotic-antimycotic.

\section{In vitro sequential selection of invasive populations from MCF-7 cells}

BD BioCoat Matrigel Invasion Chambers (for a 6-well plate; BD Biosciences, San Jose, CA) were used to select invasive populations from MCF-7 cells. MCF-7 cell suspension $\left(4 \times 10^{5}\right.$ cells/well $)$ in serum-free RPMI1640 was seeded into the upper chamber. After 60 hours' cultivation, cells that migrated through the membrane (named MCF-7-1) were harvested by trypsinization, proliferated on a dish, and then reseeded in a Matrigel Invasion Chamber. The cycle was repeated 14 times, and finally MCF-7-14 cells were obtained. In each cycle, invading cells on the underside of the chamber were fixed with $10 \%$ formalin-neutralized buffer, stained with $0.1 \%$ crystal violet, and imaged through a microscope (Axiovert 200M; Carl Zeiss, Jena, Germany) with a CCD camera (AxioCam; Carl Zeiss).

\section{Cell proliferation assay}

MCF-7 and MCF-7-14 cells $\left(5 \times 10^{3}\right.$ cells/well $)$ were seeded into 96 -well plates and cultured. The cells were counted at 24, 48, 72 and $96 \mathrm{~h}$ with a Cell Counting Kit-8 (MTT assay; Wako Pure Chemical Industries, Osaka, Japan).

\section{Western blotting}

Cell protein lysates were prepared from confluent cell cultures of MCF-7 and MCF-7-14 cells, subjected to SDSPAGE, and transferred to PVDF membranes. The membranes were blocked (5\% skim milk) and incubated with rat anti-human epidermal growth factor receptor 2, HER-2 (GeneTex, Irvine, CA) and mouse anti-estrogen receptor alpha, ER- $\alpha$ (Stressgen/Assay Designs, Ann Arbor, MI) monoclonal antibodies (mAbs), followed by the corresponding HRP-conjugated secondary antibody (GE Healthcare, Piscataway, NJ). Antibody complexes were detected with the ECL detection system (GE Healthcare).

\section{In vitro wound healing assay}

Migratory abilities of MCF-7 and MCF-7-14 cells were measured using the in vitro wound healing assay. Cells were plated on $10-\mathrm{cm}$ culture dishes and grown to $100 \%$ confluence. Wounds were created by scraping monolayer cells with a sterile pipette tip. At 0, 24, 48, 72 and $96 \mathrm{~h}$ after the creation of wounds, three different areas were imaged through an Axiovert $200 \mathrm{M}$. Wound distances were measured at each time point and expressed as the average percent of wound closure by comparing the zero time. 


\section{Xenografts}

Animal experiments were performed in accordance with the Guidelines of the Japanese Government for the Care and Use of Laboratory Animals and approved by the Institutional Animal Care and Use Committee at Tokyo University of Science and the Ethics Committee of Bio Matrix Research Inc. MCF-7 and MCF-7-14 cells were transfected with pEGFP-C1 (encoding the enhanced green fluorescence protein, EGFP; Clontech Laboratories, Mountain View, CA) using Fugene 6 Transfection Reagent (Roche, Basel, Switzerland) in serum-free medium. MCF-7 and MCF-7-14 cells stably transfected with pEGFP-C1 (named MCF-7-EGFP and MCF-7-14-EGFP, respectively) were selected by G418 treatment $(500 \mu \mathrm{g} /$ $\mathrm{ml}$ ) for 3 weeks. Suspensions of MCF-7-EGFP and MCF-7-14-EGFP cells $\left(1 \times 10^{6}\right.$ cells $\left./ 50 \mu \mathrm{l}\right)$ were mixed with the same volume of Matrigel, and injected into the fourth mammary fat pad of 10-week-old female BALB/ $\mathrm{cJ} / \mathrm{nu} / \mathrm{nu}$ mice.

\section{In vivo and ex vivo imaging of EGFP-labeled breast cancer cells}

At 4, 8 and 12 weeks after implantation of MCF-7-EGFP and MCF-7-14-EGFP cells, mice were sacrificed and scanned by a luminescence/fluorescence imaging analyzer (LAS3000; Fujifilm, Tokyo, Japan) to detect metastatic lesions. Ex vivo fluorescence imaging was also performed on necropsy samples.

\section{Histology and immunohistochemistry}

Xenografts and metastatic lesions were rapidly frozen, and $6 \mu \mathrm{m}$ thick sections were cut on a cryostat. The sections were analyzed by hematoxylin/eosin (HE) and methyl green pyronin (MGP) staining, or unstained sections were analyzed for EGFP fluorescence. For immunostaining epithelial and mesenchymal markers, mouse anti-cytokeratin (CK) 19 (A53-B/A2; 1:50 dilution; Santa Cruz Biotechnology, Santa Cruz, CA), anti-E-cadherin (67A4; 1:25; Santa Cruz Biotechnology) and anti-vimentin (V9; 1:150; Dako, Glostrup, Denmark) mAbs were used. Briefly, frozen sections were treated with $3 \% \mathrm{H}_{2} \mathrm{O}_{2}$ for $10 \mathrm{~min}$ and $5 \%$ skim milk in Tris-buffered saline with $0.2 \%$ Triton-X for $1 \mathrm{~h}$. Primary antibodies were applied for $1 \mathrm{~h}$ at room temperature. Subsequently, the sections were incubated with Simple Stain Mouse MAX PO (Nichirei Biosciences, Tokyo, Japan) or Alexa Fluor 488-conjugated goat anti-mouse IgG (1:200; Molecular Probes, Invitrogen, Carlsbad, CA) at room temperature. Diaminobenzidine (DAB) with $0.1 \% \mathrm{H}_{2} \mathrm{O}_{2}$ (Dako) was used as the final chromogen and hematoxylin for nuclear counterstaining in immunohistochemistry. In immunofluorescence, cell nuclei were counterstained with 4', 6-diamidino-2-phenylindole (DAPI). Immunostaining of the endothelial marker, CD31, was performed with rat anti-mouse CD31 mAb (MEC 13.3; 1:50; BD Biosciences) and HRP-linked goat anti-rat IgG F(ab')2 fragment (1:200; Amersham ECL, GE Healthcare). Microscopic images were acquired using an Axiovert $200 \mathrm{M}$ equipped with an AxioCam and analyzed by AxioVision software (Carl Zeiss).

\section{Immunofluorescence staining}

MCF-7, MCF-7-14 and MDA-MB-231 cells were plated on coverslips and fixed with $4 \%$ paraformaldehyde/ phosphate-buffered saline (PBS) for $15 \mathrm{~min}$ and permeabilized with $0.1 \%$ Triton X-100 in PBS for 2 min, and then incubated in PBS containing 5\% skim milk for $1 \mathrm{~h}$ at room temperature. Cells were incubated with anti-Ecadherin $(1: 100)$, anti- $\beta$-catenin $(8 \mathrm{E} 7 ; 1: 100$; Upstate Biotechnology/Millipore, Billerica, MA), anti-vimentin (1:300) and anti-fibronectin (clone 10; 1:200; BD Biosciences) $\mathrm{mAbs}$ for $1 \mathrm{~h}$ at room temperature, followed by incubation with Alexa Fluor 488-conjugated goat antimouse IgG (1:200-1:1000) and nuclear counterstaining with DAPI.

\section{RNA isolation}

MCF-7, MCF-7-14 and MDA-MB-231 cells were synchronized in S-phase with the thymidine-hydroxyurea block method. Total RNA was isolated from cells arrested in S-phase using an RNeasy Mini kit (Qiagen, Hilden, Germany).

\section{Microarray analysis}

cDNA was synthesized from total RNA isolated from MCF-7, MCF-7-14 and MDA-MB-231 cells using a One-Cycle cDNA Synthesis Kit (Affymetrix, Santa Clara, $\mathrm{CA}$ ). In vitro transcription reactions were performed using a GeneChip IVT Labeling Kit. Fifteen micrograms of the labeled cRNA was hybridized to a Human Genome U133 Plus 2.0 Array (Affymetrix). The array images were scanned and analyzed using Genechip operating software (GCOS; Affymetrix). The full microarray data set is available in the NCBI Gene Expression Omnibus public database under data series accession number GSE18903.

\section{Microarray data analysis}

Using GeneSpring GX 7.3.1 software (Agilent Technologies, Santa Clara, CA), microarray data of each chip were normalized to the $50^{\text {th }}$ percentile of the measurements on that chip. For per-gene normalization, the measurements of each probe were normalized to the median of the measurements of that probe in MCF-7, MCF-7-14 and MDA-MB-231 cell lines. Average linkage hierarchical clustering was carried out on genes filtered on detection flags ("present" in two or more cell lines) and signal intensity ( $>50$ in all cell lines). To identify 
potentially important differences in biological mechanisms regarding their invasive potential, genes up- or down-regulated $>2$-fold in both MCF-7-14 and MDAMB-231 cells compared with MCF-7 cells were selected from the filtered genes. Ingenuity Pathway Analysis software (IPA 5.0; Ingenuity Systems, Redwood City, CA) was also utilized to identify the top significant canonical pathways for these selected genes and to functionally link the most differentially expressed genes.

\section{Quantitative real-time-PCR}

cDNA was synthesized from $2 \mu \mathrm{g}$ total RNA using SuperScript III reverse transcriptase (Invitrogen). Reverse transcription (RT) was run for $1 \mathrm{~h}$ at $50^{\circ} \mathrm{C}$ and stopped by heating for $5 \mathrm{~min}$ at $85^{\circ} \mathrm{C}$. PCR was conducted in a $7900 \mathrm{HT}$ Fast Real-Time PCR System (Applied Biosystems, Foster City, CA). A $10 \mu$ reaction containing $0.2 \mu \mathrm{l} \mathrm{cDNA}, 0.5 \mu \mathrm{M}$ of each primer and $2.5 \mu$ l Power SYBR Green PCR Master Mix (Applied Biosystems) was used to monitor double-strand DNA synthesis. Primer sequences are provided in Additional file 1. Quantitative RT-PCR (qRT-PCR) was carried out following the recommended thermal profile: $95^{\circ} \mathrm{C}$ for $10 \mathrm{~min}$ (pre-incubation) followed by 40 cycles of $95^{\circ} \mathrm{C}$ for $15 \mathrm{sec}$ (denaturation) and $60^{\circ} \mathrm{C}$ for $1 \mathrm{~min}$ (annealing and elongation). Fluorescence intensity of the amplified products was measured at the end of each PCR cycle. Two runs were performed with each data point run in triplicate. Results were normalized to internal control GAPDH mRNA and if necessary, represented relative to mRNA levels of MCF-7 cells.

\section{Single-cell cloning}

MCF-7 and MCF-7-14 cells were plated on 96-well plates at a concentration of a single cell per well, which was confirmed visually. Wells containing either none or more than one cell were excluded from further analysis. Single-cell clones were cultured to allow the growth of individual colonies, which were picked and expanded in culture, and analyzed by Matrigel invasion assay and flow cytometry.

\section{Flow cytometry}

Three human breast cancer cell lines, MCF-7, MCF-714 and MDA-MB-231, and single-cell clones derived from the MCF-7 and MCF-7-14 cell lines were used in flow cytometry analysis. Cells were harvested with TrypLE Express (Invitrogen), and then suspended $\left(2 \times 10^{6}\right.$ cells/100 $\mu \mathrm{l}$ ) with Stain Buffer containing 1\% FBS (BD Biosciences). Phycoerythrin (PE)-conjugated mAbs against human CD44 (G44-26; BD Biosciences) or CD24 (ML5; BD Biosciences) were added to the cell suspension at the concentrations recommended by the manufacturer and incubated at $4^{\circ} \mathrm{C}$ in the dark for $60 \mathrm{~min}$.
The labeled cells were fixed in $100 \%$ methanol on ice for $5 \mathrm{~min}$. Flow cytometry analysis were performed in triplicate using a FACSCalibur system (BD Biosciences).

\section{Function-blocking antibody treatment}

Cells $\left(1 \times 10^{6}\right.$ cells $)$ were incubated with rat anti-human CD44 mAb (IM7; BD Biosciences) or normal rat IgG at $400 \mu \mathrm{g} / \mathrm{ml}$ for $20 \mathrm{~min}$. After preincubation, a cell proliferation assay, cell migration assay and Matrigel invasion assay were performed. Cell proliferation was assessed by MTT assay. The cell migration assay was performed using an Oris Cell Migration Assay (Platypus Technologies, Madison, WI), which comprises a 96-well plate with silicone stoppers ( $2 \mathrm{~mm}$ diameter) in each well. Following cell seeding and cell attachment $\left(2 \times 10^{4}\right.$ cells), the stoppers were removed and migration proceeded for $72 \mathrm{~h}$. Cells were then stained with crystal violet and imaged through a microscope. Matrigel Invasion Chambers (for a 24-well plate; BD Biosciences) were used to examine cell invasion. Pretreated cells $(5 \times$ $10^{4}$ cells) in serum-free RPMI1640 were seeded into the upper chamber and invading cells were fixed and stained after $60 \mathrm{~h}$ cultivation.

\section{Statistical analysis}

Data are the means \pm standard deviation (SD). Values were compared between MCF-7 and MCF-7-14 cells and between normal IgG and anti-CD44 mAb using Student's $t$ test. Comparisons among cell lines were made using analysis of variance (ANOVA) and TukeyKramer multiple comparison, where appropriate. $P<$ 0.05 was considered significant.

\section{Results}

Selection and morphological characterization of MCF-7-14 cells

MCF-7 cells were seeded into a Matrigel Invasion Chamber. After 60 hours' cultivation, cells that migrated through the Matrigel membrane (MCF-7-1) were harvested, proliferated on a dish, and then reseeded in a Matrigel Invasion Chamber. Matrigel invasive cells are rare populations within MCF-7 cells. Very few cells migrated through the Matrigel until the $8^{\text {th }}$ cycle of sequential selection (Figure $1 \mathrm{~A}$ and $1 \mathrm{~B}$ ); however, after the $9^{\text {th }}$ cycle, Matrigel invasive cells markedly increased, and finally, through 14 cycles of sequential Matrigel screening, we obtained MCF-7-14 cells with a significantly $(P<0.01)$ higher proportion of invasive cells than parental MCF-7 cells (Figure 1A and 1B). The selected MCF-7-14 cells in culture were compared with parental MCF-7 cells for morphology and proliferative capacity. MCF-7-14 cells uniquely displayed anchorageindependent growth and formed non-adherent spheres (Figure 1C); however, the proliferative capacity of 


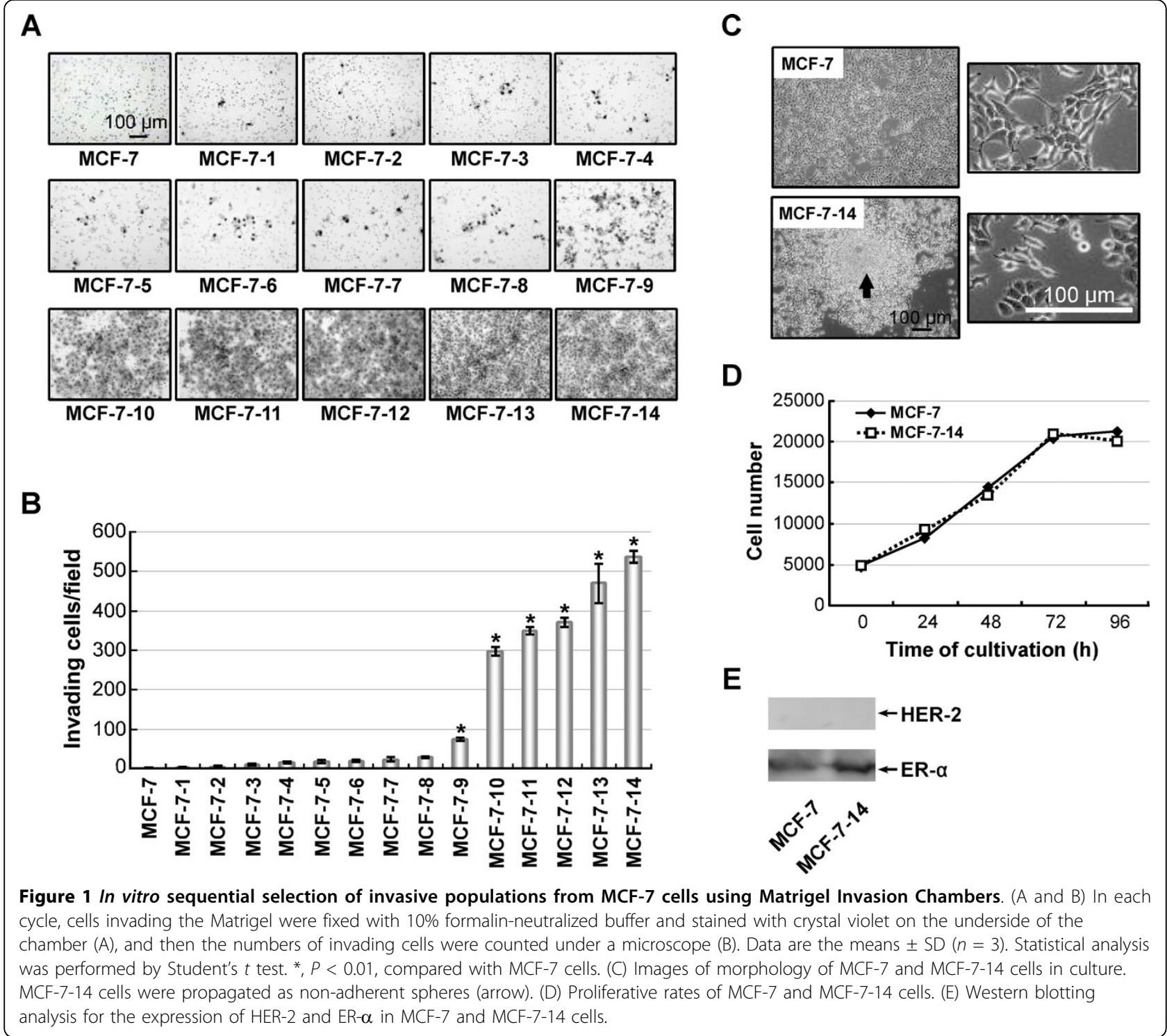

MCF-7-14 cells was similar to that of parental MCF-7 cells (Figure 1D). In addition, MCF-7-14 cells expressed ER- $\alpha$ but not HER-2, similar to MCF-7 cells (Figure 1E).

\section{Migratory and metastatic ability of MCF-7-14 cells}

The migratory ability of MCF-7-14 cells was compared with that of parental MCF-7 cells using an in vitro wound healing assay. MCF-7-14 cells displayed significantly more rapid wound closure at all time points (Figure $2 \mathrm{~A}$ and $2 \mathrm{~B}$ ), tending to protrude into the wound site, compared with MCF-7 cells (Figure 2C). Using a nude mouse orthotopic xenograft model, we assessed the in vivo metastatic ability of MCF-7-14-EGFP cells (Figure 3A). Distant metastases to the pancreas and peritoneum became detectable by fluorescence imaging 4 weeks after implanting MCF-7-14-EGFP cells and appeared in $20 \%$ of implanted animals (2/10), whereas no metastatic lesions were detected in MCF-7-EGFPbearing animals (0/10). Metastasized MCF-7-14-EGFP cells invaded the pancreatic parenchyma, as shown by HE and MGP staining, and expressed EGFP (Figure 3B). In another case, 12 weeks after implantation of MCF-714-EGFP cells, pancreas metastasis showed strong stromal and angiogenic responses closely intermingled with metastasized tumor cells, as demonstrated by immunostaining for CD31 (Figure 3C).

\section{Epithelial and mesenchymal marker expression in MCF-7-14 cells}

In immunohistochemistry, mammary xenografts and pancreas metastases generated by MCF-7-14-EGFP cells were positive for a luminal epithelial marker, CK 19, 


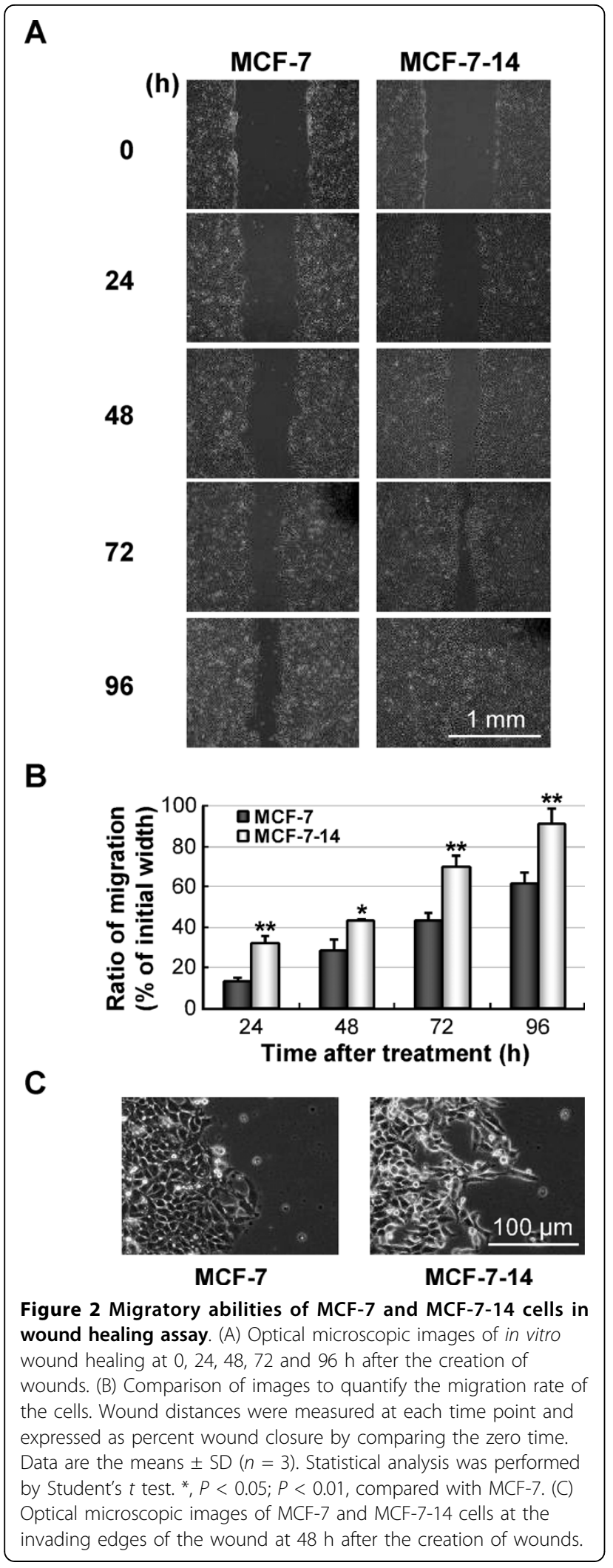

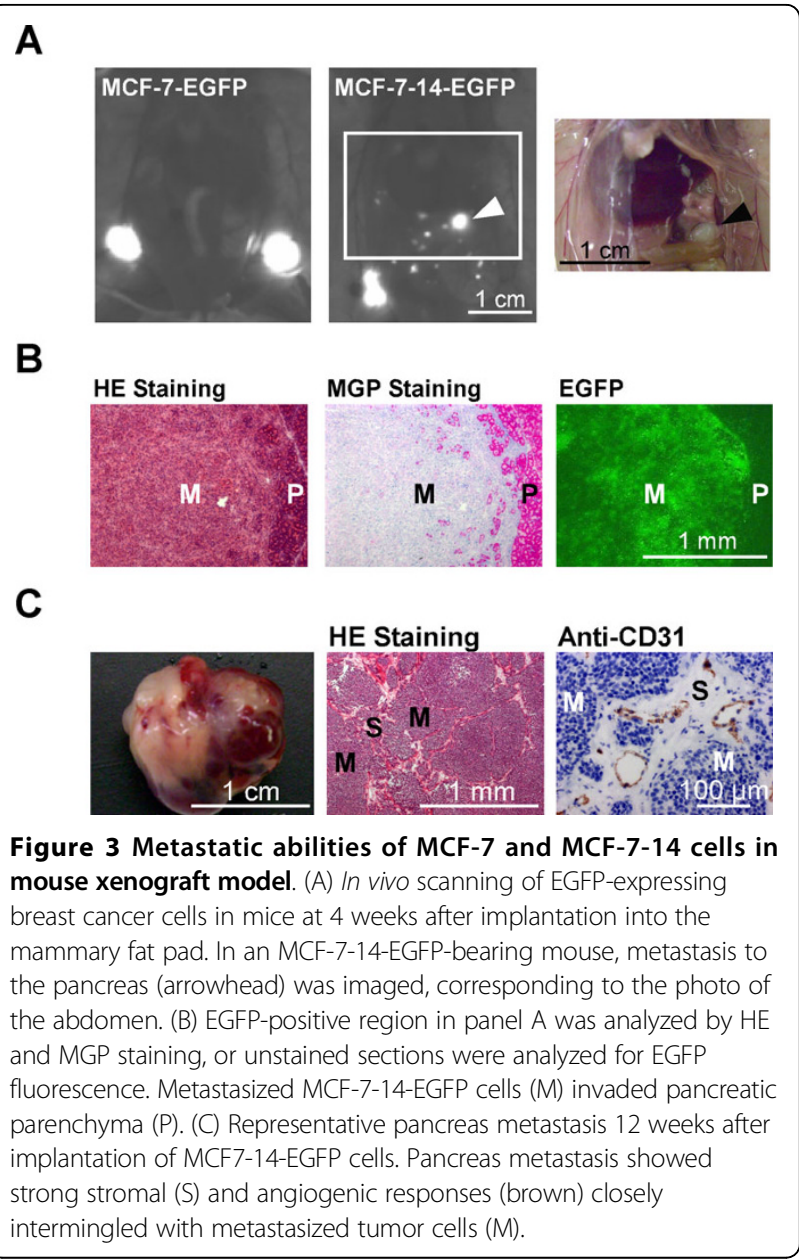

and an epithelial marker, E-cadherin, but negative for a mesenchymal marker, vimentin, similarly to MCF-7EGFP xenografts (Figure 4A). To molecularly characterize MCF-7, MCF-7-14 and MDA-MB-231 cells in more detail, we analyzed mRNA and protein expressions of epithelial and mesenchymal markers related to EMT. The mRNA expression levels of E-cadherin and mesenchymal markers, $\mathrm{N}$-cadherin and vimentin, were similar between MCF-7 and MCF-7-14 cells, while they confirmed that MDA-MB-231 cells had already undergone "complete EMT", defined by loss of epithelial markers and gain of mesenchymal markers (Figure 4B). Immunofluorescence analysis (Figure 4C) showed the localization of E-cadherin in adherent cell-cell junctions in both MCF-7 and MCF-7-14 cells, whereas E-cadherin was not detectable in MDA-MB-231 cells. In MCF-7 cells, immunofluorescence staining of $\beta$-catenin was strongly positive on the cell membrane, whereas in MDA-MB-231 cells, $\beta$-catenin was mainly expressed in 


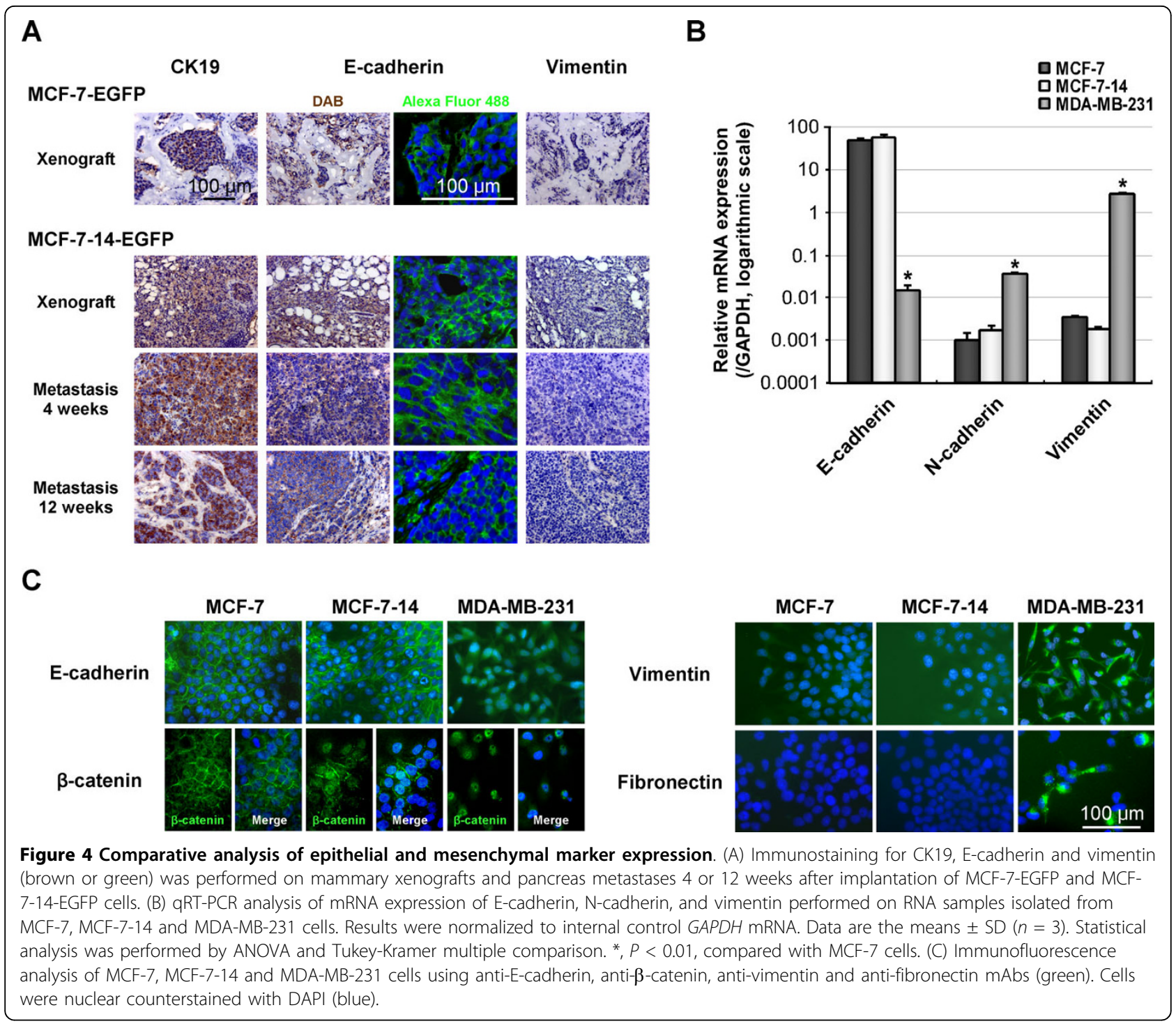

the nucleus. Interestingly, $\beta$-catenin was expressed not only on the cell membrane but also in the nucleus in MCF-7-14 cells. Immunofluorescence staining for vimentin and fibronectin demonstrated cytoplasmic localization in MDA-MB-231 cells, although they were detectable in neither MCF-7 nor MCF-7-14 cells.

144 unique genes differentially expressed in both MCF-7-14 and MDA-MB-231 cells

To identify genes associated with the invasive phenotype of breast cancer cells, we performed DNA microarray analysis and compared gene expression profiles among MCF-7, MCF-7-14 and MDA-MB-231 cells; 13,092 probe sets were detected in all samples. Hierarchical clustering based on informative probe sets showed that the MCF-7-14 cell gene expression profile was more similar to that of MCF-7 cells than MDA-MB-231 cells; however, there were some similarities between MCF-714 and MDA-MB-231 cells in gene expression (Figure 5A). Regarding their invasive potential, we selected 163 probe sets corresponding to 144 unique genes upregulated (76 probe sets, Additional file 2) or downregulated (87 probe sets, Additional file 3 ) $>2$-fold in both MCF7-14 and MDA-MB-231 cells compared with MCF-7 cells from the filtered genes (Figure 5B).

\section{Top canonical pathways and functional networks for} differentially expressed genes

To assess the relevance of the 163 probe sets to previously defined signaling pathways, canonical pathway analysis was performed using IPA 5.0. Table 1 shows the top 16 signaling pathways for the selected genes. Some of these signaling pathways were involved in regulating cell migration and stem cell function. In this 


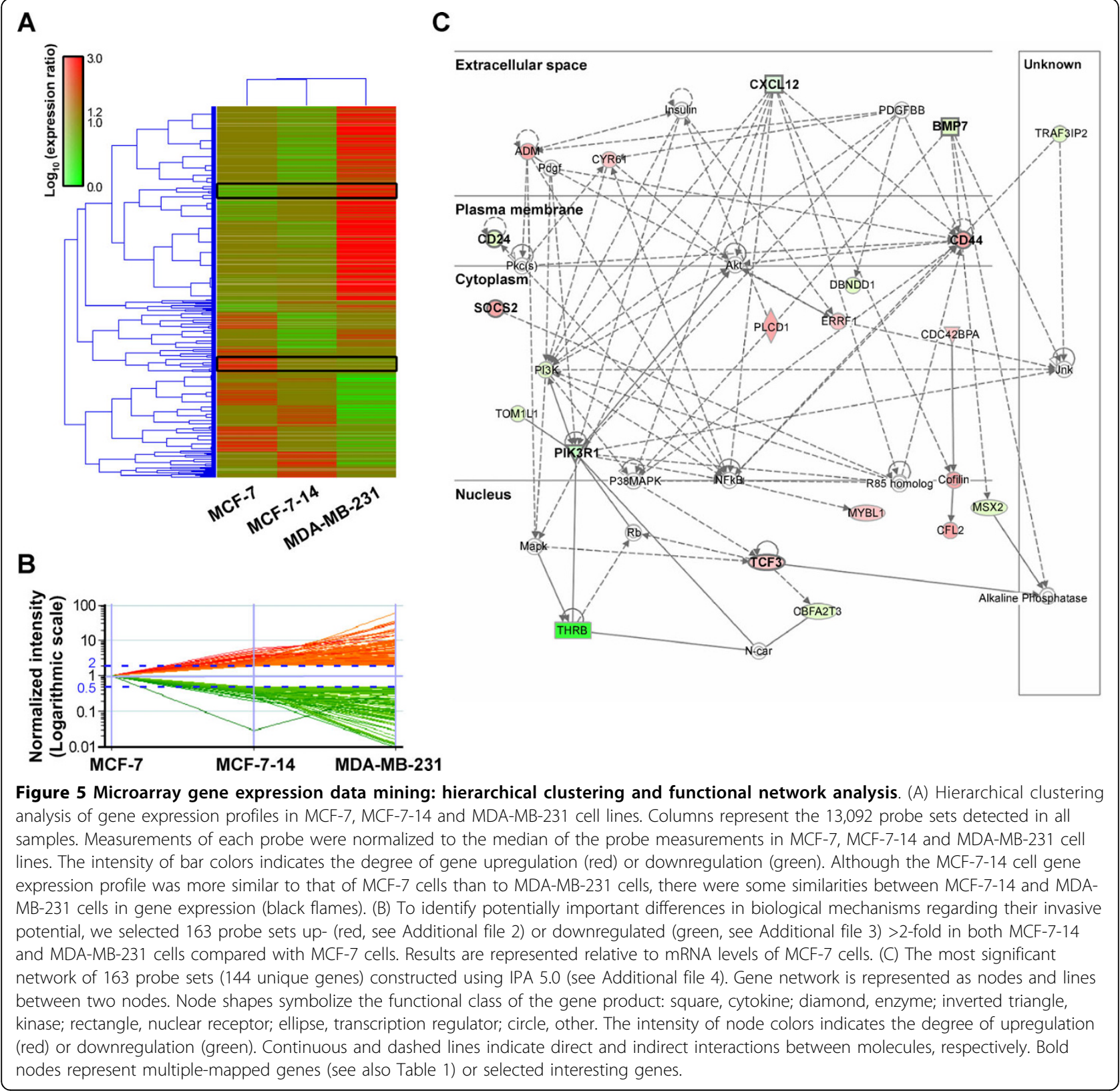

analysis, many of the selected genes involved in the top canonical pathways were multiple-mapped genes (9 genes, 74\%; Table 1). Considering the general notion that cancer metastasis is a result of multifactorial crosstalk between different molecular pathways, we generated significant functional association networks in invasive cells (see Additional file 4). The network with the highest score (Figure $5 \mathrm{C}$ ) was constructed relating to DNA replication, recombination and repair, cell cycle, and cancer. Of note, six multiple-mapped genes (PIK3R1, SOCS2, BMP7, CXCL12, CD44 and TCF3; Table 1) were mapped on the most significant network (Figure 5C).
These genes were thought to be highly associated with the migratory and invasive phenotype.

\section{Evaluation of selected interesting genes: CD44}

upregulation and CD24 downregulation in MCF-7-14 cells

Selected interesting genes (PIK3R1, SOCS2, BMP7, $C X C L 12, C D 44$ and $C D 24$ ) were evaluated by qRT-PCR using total RNA from MCF-7, MCF-7-14 and MDAMB-231 cells. The mRNA expression levels of SOCS2 and $C D 44$ were significantly $(P<0.01)$ higher in both MCF-7-14 and MDA-MB-231 cells than in MCF-7 cells. In contrast, PIK3R1, BMP7 and CD24 were significantly 
Table 1 Top signaling pathways for the 163 differentially expressed probe sets in MCF-7-14 and MDA-MB-231 cells

\begin{tabular}{ll}
\hline Pathway & $\begin{array}{l}\text { Gene mapped to canonical } \\
\text { pathways }\end{array}$ \\
\hline JAK/STAT Signaling & PIK3R1, SOCS2 \\
Xenobiotic Metabolism Signaling & ALDH3B2, MAOB, PIK3R1, \\
UGT1A6 & BMP7, CFL2, CXCL12, PIK3R1, \\
Axonal Guidance Signaling & SEMA6D \\
& BMP7, SMURF2 \\
TGF- $\beta$ Signaling & PIK3R1, SOCS2, TCF3 \\
Acute Phase Response Signaling & CD44, CXCL12, PIK3R1 \\
Leukocyte Extravasation Signaling & ERRI1, PIK3R1 \\
Neuregulin Signaling & CYR61, PIK3R1 \\
IGF-1 Signaling & PIK3R1, RPRM \\
p53 Signaling & ALDH3B2, MAOB, SLC27A2 \\
LPS/IL-1 Mediated Inhibition of RXR & \\
Function & MAOB \\
Serotonin Receptor Signaling & LFNG \\
Notch Signaling & F12 \\
Coagulation System & RPRM \\
Cell Cycle: G2/M DNA Damage & \\
Checkpoint Regulation & PIK3R1 \\
EGF Signaling & CD44, TCF3 \\
Wnt/ $\beta$-catenin Signaling &
\end{tabular}

Pathway analysis was performed on 163 probe sets (144 unique genes) up- or down-regulated $>2$-fold in both MCF-7-14 and MDA-MB-231 cells compared with MCF-7 cells (see Additional files 2 and 3) using IPA 5.0. Genes in bold are mapped to multiple top canonical pathways, and genes in bold italics are also mapped on the most significant functional network for the 163 probe sets (see also Figure 5C).

$(P<0.01)$ downregulated in MCF-7-14 and MDA-MB231 cells (Figure 6A); however, MCF-7-14 cells showed a lower degree of upregulation or downregulation than MDA-MB-231 cells. CXCL12 mRNA expression was similar between MCF-7 and MCF-7-14 cells, although it was significantly $(P<0.01)$ downregulated in MDA-MB231 cells. Furthermore, the protein expression levels of CD 44 and CD24 were analyzed by flow cytometry. MCF-7 cells expressed low levels of CD44 and high levels of CD24, whereas MDA-MB-231 cells expressed high levels of CD44 and low levels of CD24 (Figure 6B), consistent with the results of qRT-PCR; however, MCF7-14 cells showed similar levels of CD44 protein expression to MCF-7 cells (Figure 6B, left panel). Thus, singlecell clones were obtained from MCF-7 and MCF-7-14 cells, and analyzed by Matrigel invasion assay and flow cytometry. Single-cell clones derived from MCF-7-14 cells had varying invasive abilities (Figure 6C). The highly invasive cell clone (MCF-7-14 CL6, Figure 6C) displayed a higher expression of CD44 than MCF-7 and its non-invasive clone cells (Figure 6B, left panel). CD24 protein was downregulated in both MCF-7-14 and CL6 cells, compared with MCF-7 and CL17 cells (Figure 6B, right panel). Therefore, these results raise the possibility that alterations in the expression levels of genes selected by pathway and network analysis, including expression patterns of CD44 and CD24, may be accompanied by the acquisition of invasive potential in MCF-7-14 cells.

\section{Effects of anti-CD44 antibody treatment on cell migration and invasion}

To clarify whether CD44 positively goes hand in hand with increased invasiveness, we examined the effects of anti-CD $44 \mathrm{mAb}$ on cell proliferation, migration and invasion. In the cell proliferation assay in the absence of antibodies (Figure 7A), whereas MCF-7-14, similar to MCF-7 cells, reached a plateau after $72 \mathrm{~h}, \mathrm{MCF}-7-14$ CL6 cells did not show a plateau phase, but rather continued to grow at a higher growth rate than MCF-7 and MCF-7-14 cells. On the other hand, MDA-MB-231 cells showed slower growth, but reached the same level as MCF-7 cells by the end of the assay. Despite the differences in the growth rate, preincubation with anti-CD44 $\mathrm{mAb}$ had no significant effect on cell proliferation in all cell lines tested, compared with treatment with normal IgG (Figure 7B). In the cell migration assay, MCF-7-14 and its clone CL6 cells migrated as a sheet, whereas MDA-MB-231 cells migrated more rapidly and more individually (Figure 7C). In addition to the difference in the method of cell migration, the CD44 expression level differs between these cells; nevertheless, anti-CD44-mAb significantly $(P<0.01)$ decreased cell migration in both MCF-7-14 and MCF-7-14 CL6 cells as well as MDAMB-231 cells (Figure 7C and 7D). Anti-CD44-mAb also significantly $(P<0.01)$ inhibited cell invasion in these cells, although MCF-7-14 CL6 cells had a significantly higher number of invading cells than MCF-7-14 and MDA-MB-231 cells, differently from the results of the cell migration assay (Figure 7E and 7F).

\section{Discussion}

MCF-7-14 cells as a novel model for breast cancer metastasis without requiring constitutive EMT

We obtained MCF-7-14 cells that had a significantly higher proportion of invasive cells throughout the in vitro sequential selection process, although parental MCF-7 cells had few Matrigel invasive cells. In addition, we demonstrated that EGFP-labeled MCF-7-14 cells metastasized to the pancreas and peritoneum in a xenograft model. In mouse orthotopic xenograft models of breast cancer, the pancreas seems to be a relatively common metastatic site. When injected into the mammary fat pad of nude mice, $\mathrm{N}$-cadherin-expressing cells, but not control MCF-7 cells, metastasized to the liver, pancreas, salivary gland, omentum, lung, lymph nodes, and lumbar spinal muscle [11]. Murine 4T1 mammary cancer cells (expressing the pcDNA-Neo expression vector as a control; 4T1Neo cells) implanted into the axillary mammary gland of $\mathrm{BALB} / \mathrm{c}$ mice metastasized to the mesentery adjacent to 

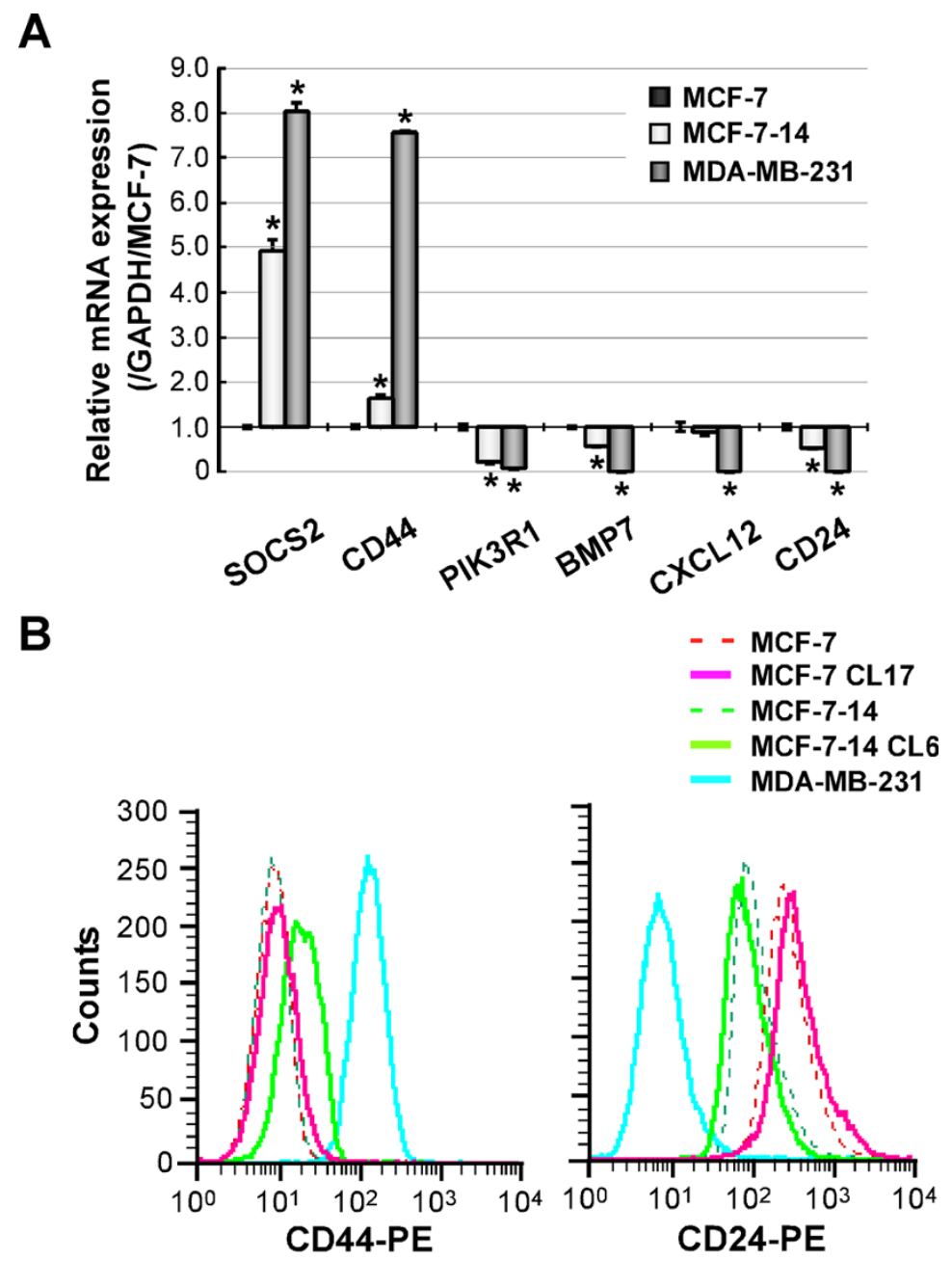

C
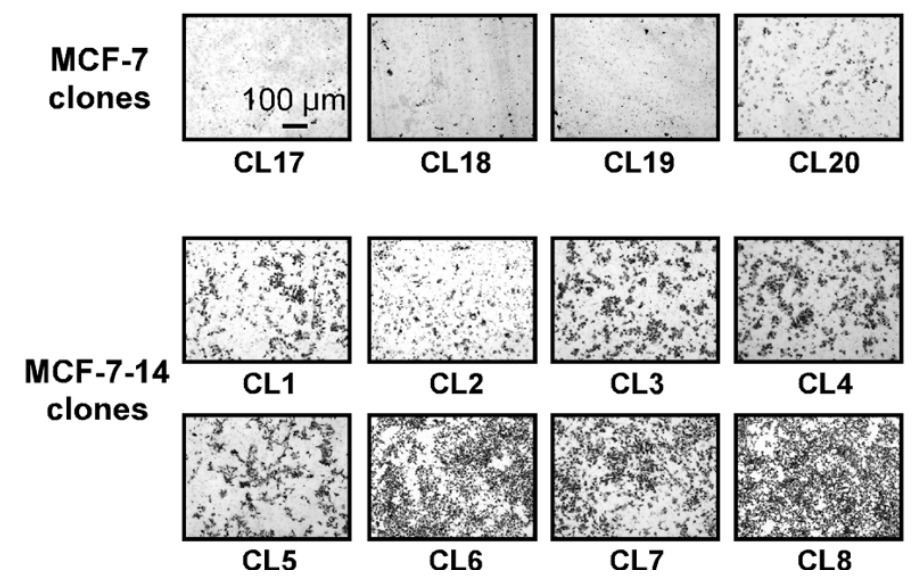

Figure 6 mRNA and protein expression of selected interesting genes. (A) qRT-PCR analysis of mRNA expression of SOCS2, CD44, PIK3R1, BMP7, CXCL12 and CD24 was performed on RNA from MCF-7, MCF-7-14 and MDA-MB-231 cells. Results were normalized to internal control GAPDH mRNA and represented relative to mRNA levels of MCF-7 cells. Data are the means \pm SD $(n=3)$. Statistical analysis was performed by ANOVA and Tukey-Kramer multiple comparison. ${ }^{*}, P<0.01$, compared with MCF-7 cells. (B) CD44 and CD24 proteins expressed on three human breast cancer cell lines (MCF-7, MCF-7-14 and MDA-MB-231) and single-cell clones derived from MCF-7 and MCF-7-14 cell lines (highly invasive MCF-7-14 CL6 and non-invasive MCF-7 CL17, panel C) were analyzed by flow cytometry. (C) Matrigel invasion assay of single-cell clones derived from MCF-7 (CL17-20) and MCF-7-14 (CL1-8) cell lines. Cells invading Matrigel were stained with crystal violet on the underside of the chamber. 


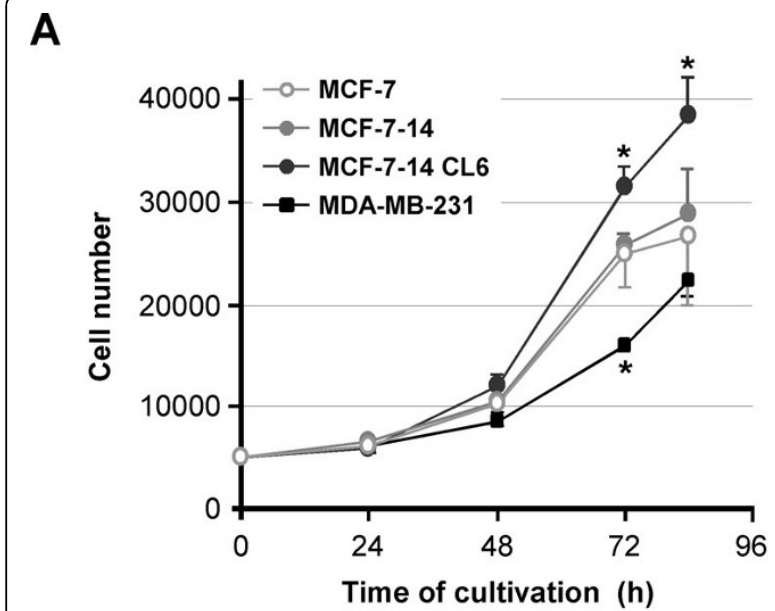

C

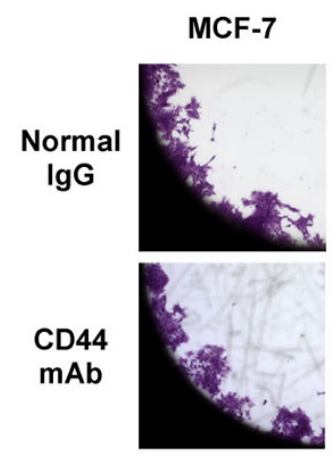

MCF-7-14
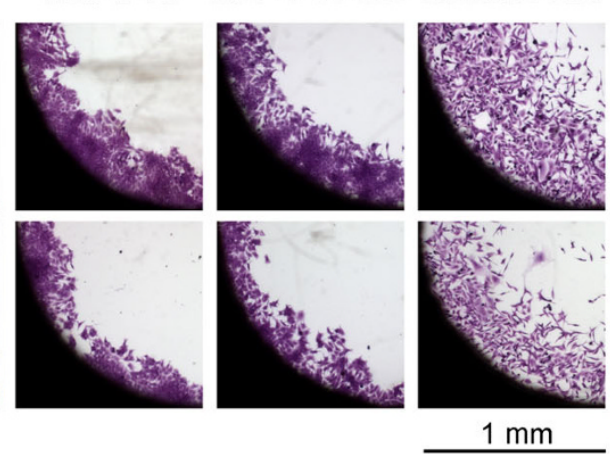

E

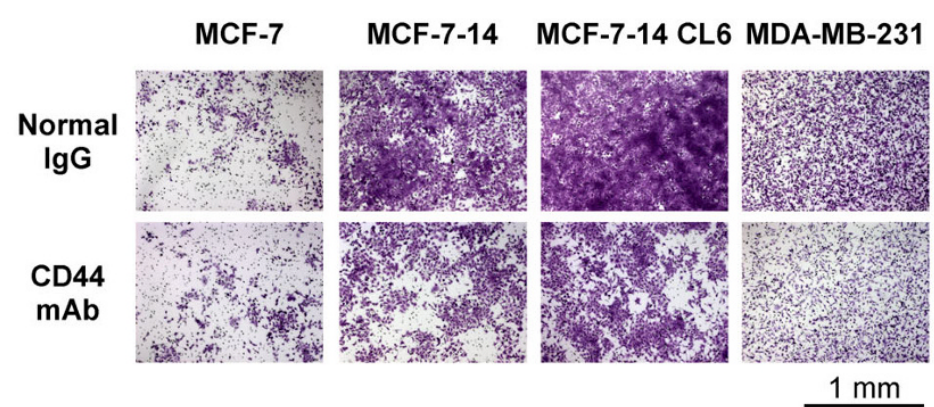

B
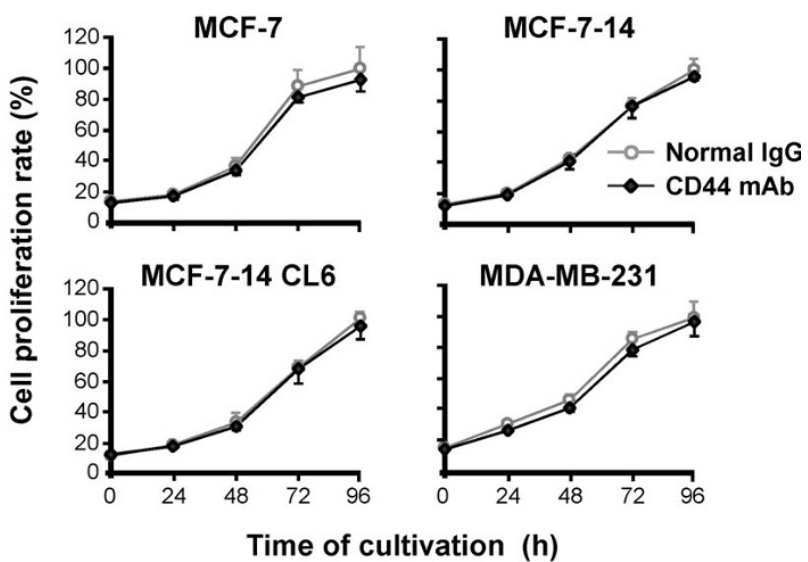

MDA-MB-231

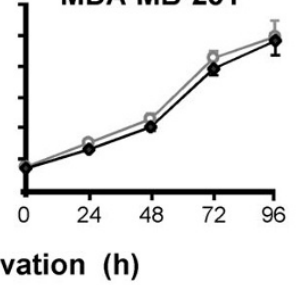

D

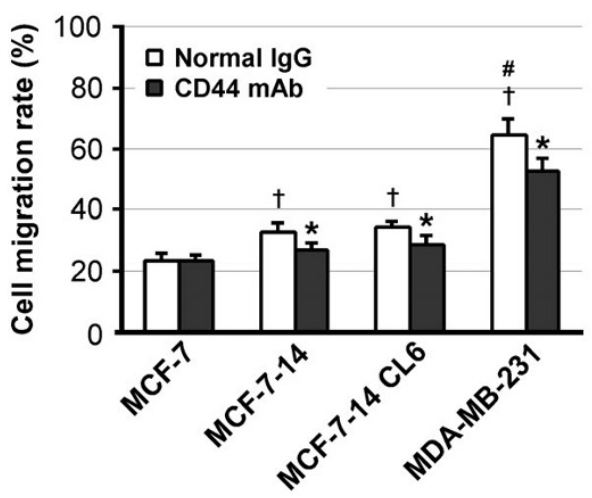

$\mathbf{F}$

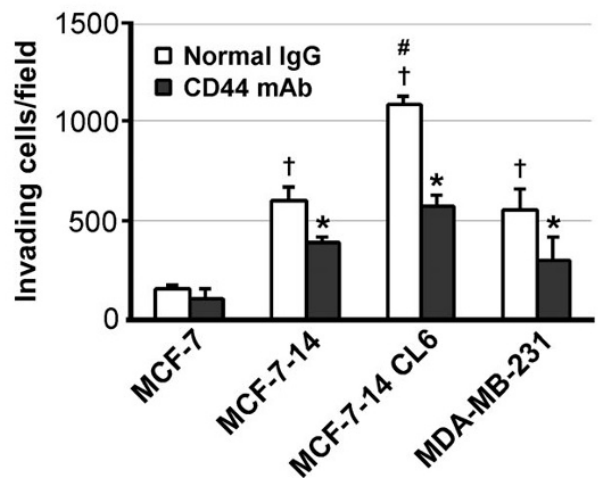

Figure 7 Effects of anti-CD44 antibody treatment on cell proliferation, migration and invasion. (A) Proliferation rates of untreated cells in culture. Data are the means \pm SD $(n=3)$. Statistical analysis was performed by ANOVA and Tukey-Kramer multiple comparison. ${ }^{*}, P<0.01$, compared with MCF-7 cells. (B) Proliferation rates of normal rat IgG-treated and anti-CD44 antibody-treated cells. In each cell line, the number of normal lgG-treated cells at $96 \mathrm{~h}$ was considered $100 \%$. Data are the means \pm SD $(n=3)$. (C) Optical microscopic images of cell migration assay at $72 \mathrm{~h}$ after removal of the stopper. Cells were fixed and stained with crystal violet. (D) Cell migration rates were expressed as percent closure of the open area by comparing the zero time. Data are the means \pm SD $(n=6)$. Statistical analysis was performed by Student's $t$ test or ANOVA/ Tukey-Kramer multiple comparison, where appropriate. ${ }^{*}, P<0.01$, compared with normal lgG-treated cells. ${ }^{\dagger}, P<0.01$, compared with MCF-7. ${ }^{\#}$, $P<0.01$, compared with MCF-7-14 and its clone CL6. (E) Matrigel invasion assay of normal rat lgG-treated and anti-CD44 antibody-treated cells. After $60 \mathrm{~h}$ cultivation, cells invading Matrigel were fixed and stained on the underside of the chamber. (F) The numbers of invading cells were counted under a microscope. Data are the means \pm SD $(n=3)$. Statistical analysis was performed by Student's $t$ test or ANOVA/Tukey-Kramer multiple comparison, where appropriate. ${ }^{*}, P<0.01$, compared with normal IgG-treated cells. ${ }^{\dagger}, P<0.01$, compared with $\mathrm{MCF}-7 .{ }^{\sharp}, P<0.01$, compared with MCF-7-14 and MDA-MB-231. 
the pancreas [12]. Despite differences in invasive ability, MCF-7-14 cells, similar to MCF-7 cells, expressed Ecadherin, but neither vimentin nor fibronectin. In the cell migration assay, MCF-7-14 and its clone CL6 cells moved as a sheet, in contrast to the more individual movements of mesenchymal MDA-MB-231 cells. Cell-sheet movement is a typical feature of epithelial cells during embryonic development and wound healing [13]; therefore, MCF-7-14 cells may be a novel model for breast cancer metastasis without requiring constitutive EMT. Complete and constitutive EMT seems not to be required for breast cancer metastasis $[1,14,15]$. In particular, Lou et al. [16] reported that $4 \mathrm{~T} 1$ cells, which express E-cadherin and $\mathrm{ZO}-1$, are migratory, invasive, and metastasize to multiple sites, and that 4T1-derived (67NR) cells, which form primary tumors but fail to metastasize, express vimentin and $\mathrm{N}$-cadherin, but not E-cadherin. The metastatic ability of breast cancer cells does not seem to strictly correlate with the genotypic and phenotypic properties of EMT per se. In addition, Tarin et al. [17] suggested that the fundamental premise that EMT occurs in real cancers is very much in doubt because of the lack of convincing evidence for the conversion of epithelial cells into mesenchymal cell lineages in vivo; however, it is possible that MCF-7 and MCF-7-14 cells can make transient EMT in vitro in a reversible fashion. For example, estrogen treatment promoted reversible EMT-like changes and collective motility in ER-positive breast cancer cells [18]. The transitory acquisition of mesenchymal characteristics could explain the difficulty in observing EMT in cancer development.

\section{Nuclear $\beta$-catenin expression and "metastable phenoptype" in MCF-7-14 cells}

On the other hand, loss of E-cadherin- $\beta$-catenin complex is an important step in the progression of many epithelial malignancies [19]. $\beta$-catenin has a dual role in the EMT; it enhances cell-cell adhesion when bound to cadherin complexes in adherens junctions and also functions as a transcriptional coactivator upon entry into the nucleus [20]. Nuclear import of $\beta$-catenin is another important player in EMT $[21,22]$. Indeed, in MDA-MB231 cells, $\beta$-catenin was mainly located in the nucleus, whereas in MCF-7 cells, $\beta$-catenin was mostly expressed on the cell membrane. Nuclear $\beta$-catenin induces a gene expression pattern favoring tumor invasion and proceeds with transition to the mesenchymal phenotype of epithelial tumor cells [23]. In MCF-7-14 cells, $\beta$-catenin was expressed not only on the cell membrane but also in the nucleus; therefore, enhanced invasive potential of MCF-7-14 cells may result from "incomplete" EMT, altering some signaling pathways. Several studies $[24,25]$ have identified a hybrid cell showing both epithelial and mesenchymal traits. These cells are referred to as a "metastable phenotype" and distinguished from both epithelial and mesenchymal cells by characteristics such as residual E-cadherin, nuclear $\beta$-catenin and sheet movement $[13,26]$. According to this categorization, MCF-7-14 cells may be just in a "metastable" cell state.

\section{Alterations in cell migration signaling in MCF-7-14 cells}

Here we analyzed which signaling pathways are associated with the enhanced migratory and invasive potential of MCF-7-14 cells. Canonical pathway analysis using IPA 5.0 identified the top 16 signaling pathways for differentially expressed genes in invasive cells. Some of these signaling pathways are involved in regulating cell migration. JAK/STAT (Janus kinase/signal transducer and activator of transcription) signaling is necessary for border cell migration in the Drosophila ovary, suggesting its relevance to the progression of cancer [27]. Axon guidance molecules and neuregulin signaling play critical roles in cancer cell invasion as well as in neuronal migration $[28,29]$. In addition, leukocytes exhibit the ability to sense and move in the direction of a chemoattractant [30]. Acute-phase response signaling modifies inflammatory responses, thereby contributing to leukocyte extravasation [31]. Directed cell movement or chemotaxis is exhibited during wound healing, angiogenesis, embryonic development, immune function, and during cancer cell metastasis [32]. Pathway and network analysis also identified a set of interesting genes, including PIK3R1, SOCS2 and BMP7. Philp et al. [33] reported the presence of somatic mutations in PIK3R1, the gene for the $\mathrm{p} 85 \alpha$ regulatory subunit of phosphatidylinositol 3 -kinase (PI3K), in primary human colon and ovarian tumors and cancer cell lines, resulting in the constitutive activation of PI3K. In addition, MCF-7-14 and MDAMB-231 cells displayed the upregulated expression of SOCS2 and downregulated expression of BMP7 compared with MCF-7 cells. JAK/STAT signaling is negatively regulated by overexpression of SOCS proteins, and SOCS2 interferes with the negative regulatory effects of SOCS1 and SOCS3 [27,34]. SOCS2 was generally upregulated in primary breast tumors that developed bone metastasis [35]. On the other hand, transforming growth factor beta (TGF- $\beta$ ) is a pro-oncogene in the later stages of tumorigenesis and appears to contribute to metastasis [36,37]. BMP7 is an antagonist of the TGF- $\beta$ pathway and can inhibit osteolytic metastasis attributable to prostate cancer [38]. Decreased BMP7 expression during carcinogenesis in the human breast contributes to the acquisition of a bone metastatic phenotype [39]. PI3K, JAK/STAT and TGF- $\beta$ signaling play key roles in cell migration, and PIK3R1, SOCS2 and BMP7 are regulatory molecules of these signaling pathways, thereby possibly contributing to metastasis development. Consequently, alterations in these signaling pathways may explain the differences in 
migratory and invasive potential between MCF-7 and MCF-7-14 cells, demonstrating the validity and usefulness of this comparative analysis.

\section{Possible relevance of MCF-7-14 cells to cancer stem cells} Canonical pathway analysis identified xenobiotic metabolism signaling as one of the top signaling pathways in invasive cells. This signaling pathway is possibly responsible for maintenance of the stem cell phenotype and multidrug resistance in breast cancer cells [40]. In addition, some of the top signaling pathways (JAK/STAT, TGF- $\beta$, epidermal growth factor and Wnt $/ \beta$-catenin signaling) overlapped the signaling pathways important for cancer stem-like cells, identified between the MCF-7 side population (SP) and non-SP cells [41]. These signaling pathways are involved in both tumorigenesis in cancer and self-renewal in embryonic stem cells [42]. Although there are no direct evidences yet, MCF-7-14 cells, which have been derived from rare cell populations with higher invasive ability within MCF-7 cells, may be possibly relevant to cancer stem-like cells. MCF7-14 cells have similar morphological characteristics to those of stem/progenitor or chemotherapy-resistant cells isolated from MCF-7 cells. Cells grown as non-adherent spherical clusters, which were isolated from breast cancer lesions or MCF-7, displayed stem/progenitor cell properties [43]. MCF-7 cells that survived chemotherapeutic treatment formed looser colonies in the monolayer, with cells at the borders tending to have more protruding filopodia [44]. Furthermore, invasive populations seem to generate both invasive and non-invasive populations resembling the cases seen in SP [45] and tumorigenic $\mathrm{CD} 44^{+} \mathrm{CD} 24^{-/ \text {low }}$ cells [8] of breast tumor cells, because the numbers of cells invading the Matrigel were very low until the $8^{\text {th }}$ cycle of in vitro sequential selection. Interestingly, MCF-7-14 cells displayed increased expression of CD44 mRNA and downregulated expression of CD24 mRNA and protein. Although MCF-7-14 cells showed cell population heterogeneity in invasiveness and CD44 protein expression, MCF-7-14derived clone MCF-7-14 CL6, which had a higher number of invading cells, displayed upregulation of CD44 and rapid and extended proliferation. However, there are no overlapping genes between our results and the gene signature identified by gene expression profiling of $\mathrm{CD} 44^{+} \mathrm{CD} 24^{-}$breast cancer stem-like cells [46]; therefore, our findings should be validated in further studies, for example, analysis of stem cell marker expression.

\section{Nuclear $\beta$-catenin and CD44 upregulation characterize invasive cell populations in breast cancer}

Mani, Weinberg and colleagues [10] found that cells that had undergone EMT exhibited $\mathrm{CD} 44^{\text {high }} / \mathrm{CD} 24^{\text {low }}$ expression, suggesting that the EMT might confer malignant properties on breast tumor cells. Although the EMT seems not to be an "all or nothing" event, upregulation of CD44 and downregulation of CD24 seem to participate in the acquisition of invasive and metastatic potential [47-49]. In this study, despite the difference in CD44 expression, treatment with CD44 $\mathrm{mAb}$ (clone IM7), which induces CD44 shedding from the cell surface [50], significantly decreased cell migration and invasion in MCF-7-14 and its clone CL6 cells as well as MDA-MB-231 cells. Although CD44 expression seems to be correlated with mesenchymal marker expression as well as with invasiveness, CD44 may be one of the most important adhesion molecules facilitating cell invasion and metastasis [51]. Furthermore, CD44 expression is, directly or indirectly, regulated by the $\beta$-catenin/Tcf- 4 signaling pathway, especially in the colorectal cancer precursor lesions, suggesting a role for CD44 in intestinal tumorigenesis [52,53]. Brabletz et al. [21] reported that nuclear $\beta$-catenin accumulates in dedifferentiated colorectal carcinoma cells at the tumor-host interface, whereas a gradual loss of nuclear $\beta$-catenin is seen towards central, well-differentiated areas of the tumor. This heterogeneous pattern of the primary tumor is recapitulated in corresponding liver metastases. Nuclear accumulation of $\beta$-catenin in colorectal cancer cells at the invasive front and in the vessels has been suggested to be a powerful predictor of liver metastasis [54]. In breast cancer, Wnt $/ \beta$-catenin activation is an important feature of basal-like breast cancers and is predictive of worse overall survival [55]. Consequently, nuclear $\beta$-catenin and upregulation of CD44 may be potential diagnostic and therapeutic targets for breast cancer metastasis.

\section{Conclusions}

Although the MCF-7 cell line has a luminal epitheliallike phenotype and lacks a CD $44^{+} / \mathrm{CD} 24^{-}$subpopulation, we obtained MCF-7-14 cells of opposite migratory and invasive capabilities from MCF-7 cells and developed a novel model for breast cancer metastasis without requiring constitutive EMT. This study better characterizes invasive breast cancer cells and provides insight into understanding the biology of breast cancer metastasis. In clinical diagnosis, ER-positive, HER2-negative breast cancer, which is defined as "luminal A" by the specific expression of an intrinsic set of genes [56], is the most common type of breast cancer and tends to have a better prognosis than the other three types (luminal B, HER-2 overexpressing, basal-like). However, the clinical behavior of luminal-type breast cancer can be markedly heterogeneous despite similar levels of ER expression [57]; therefore, a set of genes differentially regulated in MCF-7-14 cells (PIK3R1, SOCS2, BMP7, CD44 and $C D 24)$ may be useful markers to identify among good 
prognosis tumors those that will relapse and metastasize. MCF-7-14 cells, in particular, showed nuclear $\beta$-catenin expression and a similar phenotype to "metastable" cells, which are distinguished from both epithelial and mesenchymal cells [13]. In addition, MCF-7-14 and its invasive clone CL6 cells displayed increased expression of CD44 and downregulated expression of CD24 compared with MCF-7 cells. The alterations and characteristics of MCF-7-14 cells may characterize invasive cell populations in breast cancer.

\section{Additional material}

\section{Additional file 1: Primer sequences used for qRT-PCR}

Additional file 2: List of the 76 probe sets upregulated $>\mathbf{2}$-fold in both MCF-7-14 and MDA-MB-231 cells compared with MCF-7 cells.

Additional file 3: List of the 87 probe sets downregulated $>\mathbf{2}$-fold in both MCF-7-14 and MDA-MB-231 cells compared with MCF-7 cells.

Additional file 4: Top significant networks for the 163 differentially expressed probe sets (144 unique genes) in both MCF-7-14 and MDA-MB-231 cells compared with MCF-7 cells.

\begin{abstract}
Abbreviations
ANOVA: analysis of variance; CK: cytokeratin; DAB: diaminobenzidine; DAPI: 4', 6-diamidino-2-phenylindole; EGFP: enhanced green fluorescence protein; EMT: epithelial-to-mesenchymal transition; ER- $\alpha$ : estrogen receptor alpha; FBS: fetal bovine serum; HE: hematoxylin/eosin; HER-2: human epidermal growth factor receptor 2; JAK/STAT: Janus kinase/signal transducer and activator of transcription; mAb: monoclonal antibody; MGP: methyl green pyronin; PBS: phosphate-buffered saline; PE: phycoerythrin; PI3K: phosphatidylinositol 3-kinase; qRT-PCR: quantitative reverse transcription polymerase chain reaction; SD: standard deviation; SP: side population; TGF- $\beta$ : transforming growth factor beta.
\end{abstract}

\section{Acknowledgements}

This study is funded by JCR Pharmaceuticals. We are grateful to Mr. Takashi Homma and the members of the Microarray and Bioinformatics Departments for their technical assistance.

\section{Author details}

'Neo-Technology Development Division, Bio Matrix Research Inc., 105 Higashifukai, Nagareyama, Chiba 270-0101, Japan. ${ }^{2}$ Department of Biological Science and Technology, Graduate School of Industrial Science and Technology, Tokyo University of Science, 2641 Yamazaki, Noda, Chiba 2788510, Japan. ${ }^{3}$ Current Address: Technology Development Department, ATTO Corporation, Tokyo 113-0034, Japan. ${ }^{4}$ Current Address: Department of Bioproduction, Faculty of Bioindustry, Tokyo University of Agriculture, Hokkaido 099-2493, Japan. ${ }^{5}$ Current Address: Pharmaceutical BTO Unit, CAC Corporation, Tokyo 103-0015, Japan.

\section{Authors' contributions}

$\mathrm{MU}, \mathrm{HK}$ and $\mathrm{KW}$ participated in the design and coordination of the study, carried out the analyses and wrote the manuscript. Ml performed sequential selection of invasive populations from MCF-7 cells and obtained MCF-7-14 cells. HS performed function-blocking experiments and helped draft the manuscript. FO, TU and YM were responsible for the study conception, data interpretation and manuscript preparation. All authors read and approved the final manuscript.

\section{Competing interests}

MU, HS and TU are employees of Bio Matrix Research Inc. HK and KW are former employees of the company. YM is a co-founder and the COO of the company. MI, HK, MU, TU and YM are co-inventors of a pending patent entitled "MCF7-derived cell" (WO/2008/093886). This is a joint application by Bio Matrix Research Inc. and Tokyo University of Science. MU, HK, TU and YM are also co-inventors of a pending patent entitled "Methods and kits for evaluating malignancy of breast cancer" (PCT/JP2009/070078), which is filed by Bio Matrix Research Inc. FO declares no conflict of interest.

Received: 27 October 2009 Accepted: 10 August 2010

Published: 10 August 2010

\section{References}

1. Christiansen JJ, Rajasekaran AK: Reassessing epithelial to mesenchymal transition as a prerequisite for carcinoma invasion and metastasis. Cancer Res 2006, 66:8319-8326.

2. Charafe-Jauffret $E$, Ginestier $C$, Monville $F$, Finetti $P$, Adélaïde J, Cervera $N$, Fekairi S, Xerri L, Jacquemier J, Birnbaum D, Bertucci F: Gene expression profiling of breast cell lines identifies potential new basal markers. Oncogene 2006, 25:2273-2284.

3. Fillmore $C M$, Kuperwasser $C$ : Human breast cancer cell lines contain stemlike cells that self-renew, give rise to phenotypically diverse progeny and survive chemotherapy. Breast Cancer Res 2008, 10:R25.

4. Fidler IJ, Kripke ML: Metastasis results from preexisting variant cells within a malignant tumour. Science 1977, 197:893-895.

5. Chu YW, Yang PC, Yang SC, Shyu YC, Hendrix MJ, Wu R, Wu CW: Selection of invasive and metastatic subpopulations from a human lung adenocarcinoma cell line. Am J Respir Cell Mol Biol 1997, 17:353-360.

6. Cheng GZ, Chan J, Wang Q, Zhang W, Sun CD, Wang LH: Twist transcriptionally up-regulates AKT2 in breast cancer cells leading to increased migration, invasion, and resistance to paclitaxel. Cancer Res 2007, 67:1979-1987.

7. Li F, Tiede B, Massagué J, Kang Y: Beyond tumorigenesis: cancer stem cells in metastasis. Cell Research 2007, 17:3-14.

8. Al-Hajj M, Wicha MS, Benito-Hernandez A, Morrison SJ, Clarke MF: Prospective identification of tumorigenic breast cancer cells. Proc Natl Acad Sci USA 2003, 100:3983-3988.

9. Sheridan C, Kishimoto H, Fuchs RK, Mehrotra S, Bhat-Nakshatri P, Turner $\mathrm{CH}$, Goulet R Jr, Badve S, Nakshatri H: CD44 $/$ CD24 breast cancer cells exhibit enhanced invasive properties: an early step necessary for metastasis. Breast Cancer Res 2006, 8:R59.

10. Mani SA, Guo W, Liao MJ, Eaton EN, Ayyanan A, Zhou AY, Brooks M, Reinhard F, Zhang CC, Shipitsin M, Campbell LL, Polyak K, Brisken C, Yang J, Weinberg RA: The epithelial-messenchymal transition generates cells with properties of stem cells. Cell 2008, 133:704-715.

11. Hazan RB, Phillips GR, Qiao RF, Norton L, Aaronson SA: Exogenous expression of $\mathrm{N}$-cadherin in breast cancer cells induces cell migration, invasion, and metastasis. J Cell Biol 2000, 148:779-790.

12. Dong $M$, How T, Kirkbride KC, Gordon K, Lee JD, Hempel N, Kelly $P$, Moeller BJ, Marks JR, Blobe GC: The type III TGF-beta receptor suppresses breast cancer progression. J Clin Invest 2007, 117:206-217.

13. Lee JM, Dedhar S, Kalluri R, Thompson EW: The epithelial-mesenchymal transition: new insights in signaling, development, and disease. $\int$ Cell Biol 2006, 172:973-981

14. Thompson EW, Paik S, Brünner N, Sommers CL, Zugmaier G, Clarke R, Shima TB, Torri J, Donahue S, Lippman ME, Martin GR, Dickson RB: Association of increased basement membrane invasiveness with absence of estrogen receptor and expression of vimentin in human breast cancer cell lines. J Cell Physiol 1992, 150:534-544.

15. Pinkas J, Leder P: MEK1 signaling mediates transformation and metastasis of $\mathrm{EpH} 4$ mammary epithelial cells independent of an epithelial to mesenchymal transition. Cancer Res 2002, 62:4781-4790

16. Lou Y, Preobrazhenska O, auf dem Keller U, Sutcliffe M, Barclay L, McDonald PC, Roskelley C, Overall CM, Dedhar S: Epithelial-mesenchymal transition (EMT) is not sufficient for spontaneous murine breast cancer metastasis. Dev Dyn 2008, 237:2755-2768.

17. Tarin D, Thompson EW, Newgreen DF: The fallacy of epithelial mesenchymal transition in neoplasia. Cancer Res 2005, 65:5996-6000.

18. Planas-Silva MD, Waltz PK: Estrogen promotes reversible epithelial-tomesenchymal-like transition and collective motility in MCF-7 breast cancer cells. J Steroid Biochem Mol Biol 2007, 104:11-21.

19. Lim SC, Lee MS: Significance of E-cadherin/beta-catenin complex and cyclin D1 in breast cancer. Oncol Rep 2002, 9:915-928. 
20. van Es JH, Barker N, Clevers H: You Wnt some, you lose some: oncogenes in the Wnt signaling pathway. Curr Opin Genet Dev 2003, 13:28-33.

21. Brabletz T, Jung A, Spaderna S, Hlubek F, Kirchner T: Migrating cancer stem cells - an integrated concept of malignant tumor progression. Nat Rev Cancer 2005, 5:744-749.

22. Yang L, Lin C, Liu ZR: P68 RNA helicase mediates PDGF-induced epithelial mesenchymal transition by displacing Axin from beta-catenin. Cell 2006 127:139-155.

23. Schmalhofer O, Brabletz S, Brabletz T: E-cadherin, beta-catenin, and ZEB1 in malignant progression of cancer. Cancer Metastasis Rev 2009, 28:151-166.

24. Ackland ML, Newgreen DF, Fridman M, Waltham MC, Arvanitis A, Minichiello J, Price JT, Thompson EW: Epidermal growth factor-induced epithelio-mesenchymal transition in human breast carcinoma cells. Lab Invest 2003, 83:435-448.

25. Chaffer CL, Brennan JP, Slavin JL, Blick T, Thompson EW, Williams ED: Mesenchymal-to-epithelial transition facilitates bladder cancer metastasis: role of fibroblast growth factor receptor-2. Cancer Res 2006, 66:11271-11278.

26. Klymkowsky MW, Savagner P: Epithelial-mesenchymal transition: a cancer researcher's conceptual friend and foe. Am J Pathol 2009, 174:1588-1593.

27. Silver DL, Geisbrecht ER, Montell DJ: Requirement for JAK/STAT signaling throughout border cell migration in Drosophila. Development 2005, 132:3483-3492.

28. Chédotal A: Chemotropic axon guidance molecules in tumorigenesis. Prog Exp Tumor Res 2007, 39:78-90.

29. Ritch PA, Carroll SL, Sontheimer H: Neuregulin-1 enhances motility and migration of human astrocytic glioma cells. J Biol Chem 2003, 278:20971-20978.

30. Servant G, Weiner OD, Herzmark P, Balla T, Sedat JW, Bourne HR: Polarization of chemoattractant receptor signaling during neutrophil chemotaxis. Science 2000, 287:1037-1040.

31. Suffredini AF, Fantuzzi G, Badolato R, Oppenheim JJ, O'Grady NP: New insights into the biology of the acute phase response. J Clin Immunol 1999, 19:203-214.

32. Lauffenburger DA, Horwitz A: Cell migration: a physiologically integrated molecular process. Cell 1996, 84:359-369.

33. Philp AJ, Campbell IG, Leet C, Vincan E, Rockman SP, Whitehead RH, Thomas RJ, Phillips WA: The phosphatidylinositol 3'-kinase p85 $\alpha$ genes is an oncogene in human ovarian and colon tumors. Cancer Res 2001, 61:7426-7429.

34. Piessevaux J, Lavens D, Montoye T, Wauman J, Catteeuw D, Vandekerckhove J, Belsham D, Peelman F, Tavernier J: Functional crossmodulation between SOCS proteins can stimulate cytokine signaling J Biol Chem 2006, 281:32953-32966.

35. Minn AJ, Kang Y, Serganova I, Gupta GP, Giri DD, Doubrovin M, Ponomarev V, Gerald WL, Blasberg R, Massagué J: Distinct organ-specific metastatic potential of individual breast cancer cells and primary tumors. J Clin Invest 2005, 115:44-55.

36. Roberts $A B$, Wakefield $L M$ : The two faces of transforming growth factor $\beta$ in carcinogenesis. Proc Natl Acad Sci USA 2003, 100:8621-8623.

37. Welch DR, Fabra A, Nakajima M: Transforming growth factor $\beta$ stimulates mammary adenocarcinoma cell invasion and metastatic potential. Proc Natl Acad Sci USA 1990, 87:7678-7682

38. Fournier PG, Guise TA: BMP7: a new bone metastases prevention? Am J Pathol 2007, 171:739-743.

39. Buijs JT, Henriquez NV, van Overveld PG, van der Horst G, Que I, Schwaninger R, Rentsch C, Ten Dijke P, Cleton-Jansen AM, Driouch $K$ Lidereau R, Bachelier R, Vukicevic S, Clézardin P, Papapoulos SE, Cecchini MG, Löwik CW, van der Pluijm G: Bone morphogenetic protein 7 in the development and treatment of bone metastases from breast cancer. Cancer Res 2007, 67:8742-8751.

40. Doyle LA, Yang W, Abruzzo LV, Krogmann T, Gao Y, Rishi AK, Ross DD: A multidrug resistance transporter from human MCF-7 breast cancer cells. Proc Natl Acad Sci USA 1998, 95:15665-15670.

41. Zhou J, Wulfkuhle J, Zhang H, Gu P, Yang Y, Deng J, Margolick JB, Liotta LA, Petricoin $E$, Zhang $Y$ : Activation of the PTEN/mTOR/STAT3 pathway in breast cancer stem-like cells is required for viability and maintenance. Proc Natl Acad Sci USA 2007, 104:16158-16163.

42. Dreesen $\mathrm{O}$, Brivanlou $\mathrm{AH}$ : Signaling pathways in cancer and embryonic stem cells. Stem Cell Rev 2007, 3:7-17.
43. Ponti D, Costa A, Zaffaroni N, Pratesi G, Petrangolini G, Coradini D, Pilotti S, Pierotti MA, Daidone MG: Isolation and in vitro propagation of tumorigenic breast cancer cells with stem/progenitor cell properties. Cancer Res 2005, 65:5506-5511.

44. De Larco JE, Wuertz BRK, Manivel JC, Furcht LT: Progression and enhancement of metastatic potential after exposure of tumor cells to chemotherapeutic agents. Cancer Res 2001, 61:2857-2861.

45. Yin L, Castagnino P, Assoian RK: ABCG2 expression and side population abundance regulated by a transforming growth factor $\beta$-directed epithelial-mesenchymal transition. Cancer Res 2008, 68:800-807.

46. Liu R, Wang X, Chen GY, Dalerba P, Gurney A, Hoey T, Sherlock G, Lewicki J, Shedden K, Clarke MF: The prognostic role of a gene signature from tumorigenic breast-cancer cells. N Engl J Med 2007, 356:217-226.

47. Hill A, McFarlane S, Mulligan K, Gillespie H, Draffin JE, Trimble A, Ouhtit A, Johnston PG, Harkin DP, McCormick D, Waugh DJ: Cortactin underpins CD44-promoted invasion and adhesion of breast cancer cells to bone marrow endothelial cells. Oncogene 2006, 25:6079-6091.

48. Schabath $H$, Runz S, Joumaa S, Altevogt P: CD24 affects CXCR4 function in pre-B lymphocytes and breast carcinoma cells. J Cell Sci 2006, 119:314-325.

49. Müller A, Homey B, Soto H, Ge N, Catron D, Buchanan ME, McClanahan T, Murphy E, Yuan W, Wagner SN, Barrera JL, Mohar A, Verástegui E, Zlotnik A: Involvement of chemokine receptors in breast cancer metastasis. Nature 2001, 410:50-56.

50. Katoh S, Matsumoto N, Kawakita K, Tominaga A, Kincade PW, Matsukura S: A role for CD44 in an antigen-induced murine model of pulmonary eosinophilia. J Clin Invest 2003, 111:1563-1570.

51. Hamada J, Sawamura Y, Van Meir EG: CD44 expression and growth factors. Front Biosci 1998, 3:d657-d664.

52. Wielenga VJ, Smits R, Korinek V, Smit L, Kielman M, Fodde R, Clevers H, Pals ST: Expression of CD44 in Apc and Tcf mutant mice implies regulation by the WNT pathway. Am J Pathol 1999, 154:515-523.

53. Zeilstra J, Joosten SP, Dokter M, Verwiel E, Spaargaren M, Pals ST: Deletion of the WNT target and cancer stem cell marker CD44 in Apc(Min/+) mice attenuates intestinal tumorigenesis. Cancer Res 2008, 68:3655-3661.

54. Suzuki H, Masuda N, Shimura T, Araki K, Kobayashi T, Tsutsumi S, Asao T, Kuwano $\mathrm{H}$ : Nuclear beta-catenin expression at the invasive front and in the vessels predicts liver metastasis in colorectal carcinoma. Anticancer Res 2008, 28:1821-1830.

55. Khramtsov Al, Khramtsova GF, Tretiakova M, Huo D, Olopade Ol, Goss KH: Wnt/beta-catenin pathway activation is enriched in basal- like breast cancers and predicts poor outcome. Am J Pathol 2010, 176:2911-2920.

56. Sørlie T, Tibshirani R, Parker J, Hastie T, Marron JS, Nobel A, Deng S, Johnsen H, Pesich R, Geisler S, Demeter J, Perou CM, Lønning PE, Brown PO, Børresen-Dale AL, Botstein D: Repeated observation of breast tumor subtypes in independent gene expression data sets. Proc Natl Acad Sci USA 2003, 100:8418-8423.

57. Loi S: Molecular analysis of hormone receptor positive (luminal) breast cancers: what have we learnt? Eur J Cancer 2008, 44:2813-2818.

\section{Pre-publication history}

The pre-publication history for this paper can be accessed here: http://www.biomedcentral.com/1471-2407/10/414/prepub

\section{doi:10.1186/1471-2407-10-414}

Cite this article as: Uchino et al:: Nuclear $\beta$-catenin and CD44 upregulation characterize invasive cell populations in non-aggressive MCF-7 breast cancer cells. BMC Cancer 2010 10:414. 